\title{
An Experimental Study on the Simultaneous Phenol and Chromium Removal From Water Using Titanium Dioxide Photocatalyst
}

\author{
Elaheh Faghih Nasiri ${ }^{a}$, Daryoush Yousefi Kebria ${ }^{\text {b,c*}}$, Farhad Qaderi ${ }^{b}$ \\ ${ }^{a}$ MSc. Student, Department of Civil-Environmental Engineering, Babol Noshirvani University of Technology, Iran . \\ ${ }^{b}$ Department of Civil-Environmental Engineering, Babol Noshirvani University of Technology, Iran. \\ ${ }^{c}$ Head Of CSNRC, Water Research Institute,Caspian Sea National Research Center, Iran.
}

Received 14 January 2018; Accepted 10 March 2018

\begin{abstract}
Organic pollutants along with heavy metals and organic metal compounds may cause abnormal changes in physical and chemical parameters (acidity, alkalinity, salinity, color, smell and taste) of aquatic ecosystems and are among the serious threats of environmental health, especially the water resources. In this study, the effect of titanium dioxide photocatalyst with different concentrations $(50,100,200,500$ and $1000 \mathrm{mg} / \mathrm{l})$ on the simultaneous removal of phenol and heavy metal (chromium) from aqueous solution of the closed system was investigated. In order to determine the optimal concentrations of photocatalyst, all the tests were conducted in $\mathrm{pH}=7$, using ultraviolet light with 100 watt power. The highest rate of phenol and chromium removal was observed at concentration of $100 \mathrm{mg} / \mathrm{ml}$ which was equal to $72.3 \%$ and $67.2 \%$, respectively. Study of the reaction kinetics showed that the reactions of phenol and chromium removal were zero and firstorder, respectively.
\end{abstract}

Keywords: Photocatalyst; Ultraviolet Radiation; Phenol; Chromium; Titanium Dioxide.

\section{Introduction}

As Iran is located in a dry and semi-arid region, exploitation of unconventional water resources can be one of the suitable methods to compensate for water deficiency. Pollutants such as heavy metals are stable in these water sources and may cause environmental pollution and alteration of the physical and chemical parameters of the water. Due to their availability for living organisms, these pollutants may endanger the health of aquatic ecosystems, hence, purification these pollutants sounds essential [1].

Heavy metals such as lead, cadmium, mercury, nickel and zinc in various types of bread and lead, cadmium, mercury, aluminum, arsenic, zinc, copper and iron in various kinds of salts are among the environmental pollutants; and human exposure to some of them through water and food can result in chronic and sometimes dangerous acute toxicities. Large quantities of natural and human-made heavy metals enter the environment, and the rate of their entry through synthetic ways goes far beyond their harvest by natural processes. Aquatic systems are naturally the final destination of these metals. The source of these pollutants in water includes household wastewater, chemical discharge, pesticides, insecticides and herbivores, industrial discharges, radioactive wastewater, petroleum hydrocarbons and dyes. These pollutants are divided into two types: degradable and non-degradable. Non-degradable pollutants include heavy metal compounds and salts, long-chain phenolic compounds and pesticides accumulated in the environment; they can affect the food chain and biological organisms in water. The increased concentration of these substances has adverse effects on fish, other aquatic organisms and even aquatic plants. The first factor indicating the effects of metals pollutants in an

\footnotetext{
* Corresponding author: dy.kebria@nit.ac.ir

$>$ This is an open access article under the CC-BY license (https://creativecommons.org/licenses/by/4.0/).

(C) Authors retain all copyrights. 
ecosystem is the presence of heavy metals in the biomass of the contaminated area which can put human health in danger. Accumulation of heavy metals in water, air and soil is a very significant environmental problem [2].

Chromium is among the heavy metals which can be observed in industrial sites. This pollutant is mainly available in soil and water in two forms: hexavalent chromium (chromium (VI) and chromium (III)/ hexavalent chromium is toxic and can form water-soluble compounds and has high mobility. Depending on the acidity, chromium concentration and aquatic environment chemistry, chromium (VI) can be observed in the form of chromate $\left(\mathrm{CrO}_{4}{ }^{2-}\right), \operatorname{dichromate}\left(\mathrm{Cr}_{2} \mathrm{O}_{7}{ }^{2-}\right)$ and hydrogen chromate $\left(\mathrm{HCrO}^{4-}\right)$ [3].

Common compounds of trivalent chromium such as $\mathrm{CrOH}^{+}, \mathrm{Cr}(\mathrm{OH})^{2+}, \mathrm{Cr}(\mathrm{OH})_{3}$ and $\mathrm{Cr}(\mathrm{OH})^{4-}$ have high surficial absorption toward soil and can form insoluble hydroxides in the aquatic environments and sediment [4].

According to the list of United States Environmental Protection Agency (US EPA), in 1986, about 1000 sites were identified in this country which were contaminated by dangerous pollutants and chromium was considered as the second highest contaminating metal in US USEPA (1995a and 1995b). Textile industry, pigment production, leather processing, metal plating, iron production, mining, metal welding and fossil fuel combustion were among the major $\mathrm{Cr}$ contaminating industries [5,6]. To avoid chromium toxicity and also to control its concentration, various standard levels have been defined. For example, world health organization (WHO) declared the concentration of chromium in drinking water as $0.05 \mathrm{mg} / \mathrm{l}[7]$.

With chemical formula of $\mathrm{C}_{6} \mathrm{H}_{5} \mathrm{OH}$, phenol is among the derivatives of hydroxyl benzene and is formed through linkage of a hydroxyl group to a benzene ring. This compound is found in natural and drinking waters, petrochemical and pharmaceutical wastewaters as well as plastic and resin production industries; therefore, it is of crucial importance [8]. This substance is also known as hydroxyl benzene and carbolic acid. High tendency of phenol to make compound with chorus will give rise to formation of chlorophenols which is more toxic than phenol and is resistant against degradation [9]. Permitted level of phenol is $0.5 \mathrm{mg} / \mathrm{l}$, based on WHO [10].

So far, various methods including activated carbon, microbial decomposition, chemical oxidation and solvent extraction have been developed for phenol removal; while, for removing chromium, surface adsorption techniques (limonite, bauxite, montmorillonite, graphene, ....), extraction, membrane, ion exchange (livatite resin, synthetic resin, ...), electrochemical methods, biological methods, sequestration, nanotechnology (nanoparticles, carbon nanotubes) have been employed [11-14]. Furthermore, the use of photocatalyst is one of the new approaches for removing pollutants. Photocatalysts are catalysts which are activated at the presence of light [15]. Nano-scaled titanium dioxide photocatalyst has a very high surface-to-volume ratio and possesses excellent photocatalytic properties, its non-toxic with high oxidation capability, and low synthesizing cost are among the other benefits of this nanoparticle [16].

A study by De Lima et al. addressed treatment of industrial wastewater by $\mathrm{TiO}_{2}$ photocatalyst under sun radiation in the acidic range. The results showed that the minimum removal efficiency was $62 \%$ and $60 \%$ for chromium (VI) and organic substances [17].

Satyro et al. investigated (Ethylenediamine-disuccinic acids) EDDs and copper removal from water by use of $\mathrm{TiO}_{2}$ under UV radiation. $100 \%$ EDDs and Cu (II) conversions were observed however, mineralization was less than $24 \%$. Data analysis showed that molar consumption of $\mathrm{Cu}$ (II) to EDDs is near to 2 [18].

Chromium (VI) removal from water by $\mathrm{Au} / \mathrm{Cu}-\mathrm{TiO}_{2}$ nanoparticles was conducted by Gondal et al. the nanoparticles were synthesized by Sol-gel method and resulted in $96 \%$ photocatalytic reduction of chromium (VI) without addition of any additives [19].

In a research carried out in 2015 on photocatalytic reduction of chromium by $\mathrm{ZnO} / \mathrm{TiO}_{2}$, the removal efficiency was 99.99\% and the level of removal in this state was more than the conditions in which $\mathrm{TiO}_{2}$ and $\mathrm{ZnO}$ were used separately. In these two conditions chromium removal was $86.07 \%$ and $82.33 \%$, respectively [20].

In 2016, reduction of chromium (VI) to chromium (III) was conducted by Djellabi et al in which titanium dioxide pohotocatalysts were employed. After 2 hours, 39.75\% of chromium (III) was observed in the form of sedimentation on surface of $\mathrm{TiO}_{2}, 60.25 \%$ of that was observed in the solution [21].

The results of Nguyen et al. obtained from studying the effect of methanol on $\mathrm{Cd}$ degradation by $\mathrm{TiO}_{2}$ photocatalyst revealed that $\mathrm{Cd}$ removal efficiency at the presence and without methanol was obtained as $7 \%$ and $30 \%$, respectively [22].

Simultaneous removal of $\mathrm{Cd}$ (II) and phenol by use of $\mathrm{TiO}_{2}$ was conducted through alkaline-acidic hydrothermal method by Lie et al. in this absorption and photocatalyst system, the removal of Cd (II) and phenol could reach to $99.6 \%$ and $99.7 \%$ [23].

Photocatalytic reduction under mutual effect of chromium (VI) ions and phenol in modified polymer of $\mathrm{TiO}_{2}$ under visible radiation was investigated by Zhang et al. optimal ratio of phenol to chromium was 1:1 and in lower rations the 
reduction occurred slower [24].

Samarghandi et al. investigated simultaneous removal of phenol and heavy metals such as $\mathrm{Cd}$ and $\mathrm{Pb}$ at $\mathrm{pH}$ values of 3, 5, 7 and 11 for 180 min. optimal phenol and Cd removal was observed at $\mathrm{pH}$ value of 11 which was $76 \%$ and $97.7 \%$, respectively. For lead, the removal was $98.8 \%$ in all $\mathrm{pH}$ values [25].

A study was conducted by Papadam et al . in 2007, where photocatalytic removal of chromium (VI) by $\mathrm{TiO}_{2}$ was investigated at the presence or absence of organic compounds. A definite synergic effect was observed between photocatalytic reduction of chromium (VI) and organic compounds on the photocatalyst with largest aspect ratio [26].

Limited number of studies has addressed simultaneous removal of heavy metals and organic compounds. This study investigated the interaction (oxidation and reduction) of phenol and chromium (VI) pollutants in normal condition and also under application of photonanocatalystic process of $\mathrm{TiO}_{2}$ under $\mathrm{UV}$ radiation in simultaneous removal of these two pollutants from water in a neutral and closed environment of laboratory. The kinetics $\mathrm{f}$ the reactions were investigated and the optimal condition was determined.

\section{Materials and Methods}

\subsection{Materials}

\subsubsection{Phenol and Chromium}

This substance with chemical formula of $\mathrm{C}_{6} \mathrm{H}_{5} \mathrm{OH}$ was prepared from Merck Company (Germany). Hexavalent chromium was also purchased in the form of dichromate potassium salt $\left(\mathrm{K}_{2} \mathrm{Cr}_{2} \mathrm{O}_{7}\right)$ from the same company.

\subsubsection{Nanocatalyst}

$\mathrm{TiO}_{2}$ nanoparticles (a white substance produced by US Research Nanomaterials) in two phases of rutile and anatase (20, and $80 \%$, respectively) with purity of $99 \%$ was used. The impurities included $\mathrm{Al}, \mathrm{Mg}, \mathrm{Si}, \mathrm{Ca}, \mathrm{S}$ and $\mathrm{Nb}$. The size of these nanoparticles was $20 \mathrm{~nm}$ with nominal specific weight of $0.46 \mathrm{~g} / \mathrm{ml}$ (Figure 1).

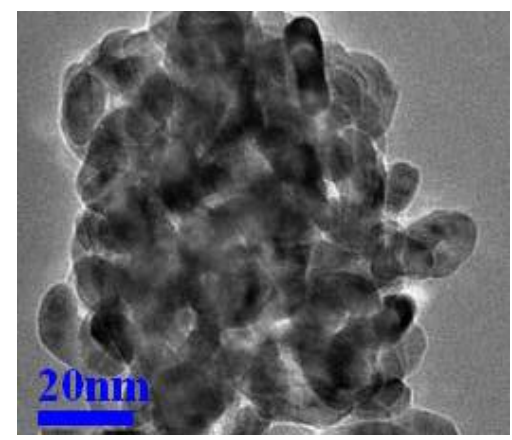

Figure 1. Titanium dioxide nanoparticles

\subsubsection{Light Source}

UV lamps with power of $25 \mathrm{~W}$ with C type possessing wavelength below $280 \mathrm{~nm}$ (made in Taiwan) were used in this study. 25-W lamps were placed in parallel to reach to power of $100 \mathrm{~W}$.

\subsection{Method}

To investigate the interaction between the two materials and the rate of their removal in the presence of the other substance, phenol and chromium with ratio of $1: 1$ and concentration f $50 \mathrm{mg} / \mathrm{l}$ were added to 3250 - $\mathrm{ml}$ beakers without nanoparticles and in the absence of UV radiation. Then they were stirred (RTC basic, IKA) for $2 \mathrm{~h}$. then, solutions with the similar concentrations of pollutants along with 50,100,200, 500 and $1000 \mathrm{mg} / \mathrm{l}$ of nanoparticles were investigated under 100-W UV radiation to determine the amount of pollutant removal (Fig.2). All the experiments were conducted in closed systems under neutral condition and in $\mathrm{pH}=7$ in triplicates.

Measurement of phenol and chromium concentration was performed by spectrophotometer (UV/VIS S21000, UNICO, US) by use of EPA 9065 [27] and EPA 7196A [28], respectively. Finally the kinetics of pollutant removal and the order of reaction were determined. 


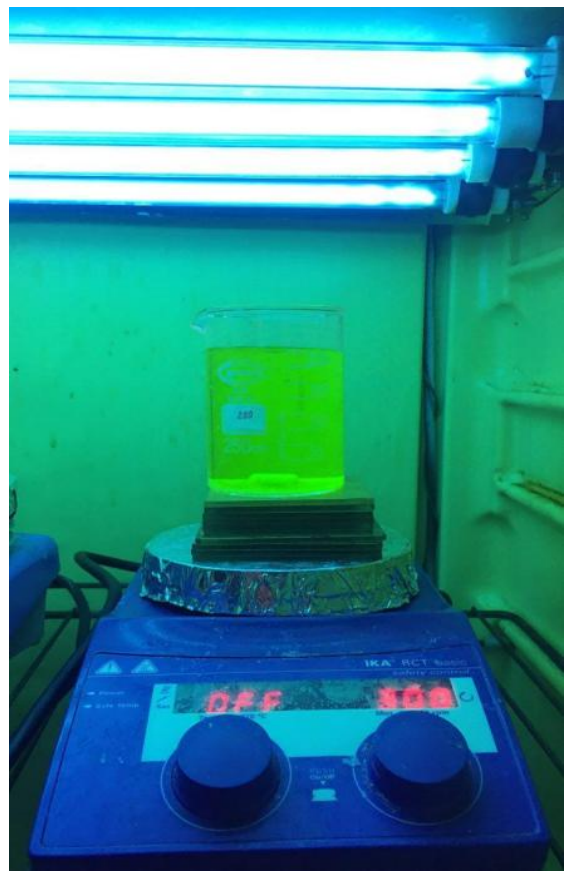

Figure 2. Chromium and phenol removal system by use of nanoparticles in the form of slurry

\section{Results and Discussions}

\subsection{Mutual Effects of Phenol and Chromium in a Closed System without Photocatalyst and UV Radiation}

The results of mutual interaction of phenol and chromium pollutants with concentrations of $50 \mathrm{mg} / \mathrm{l}$ for $3 \mathrm{~h}$ are shown in Figure 1.

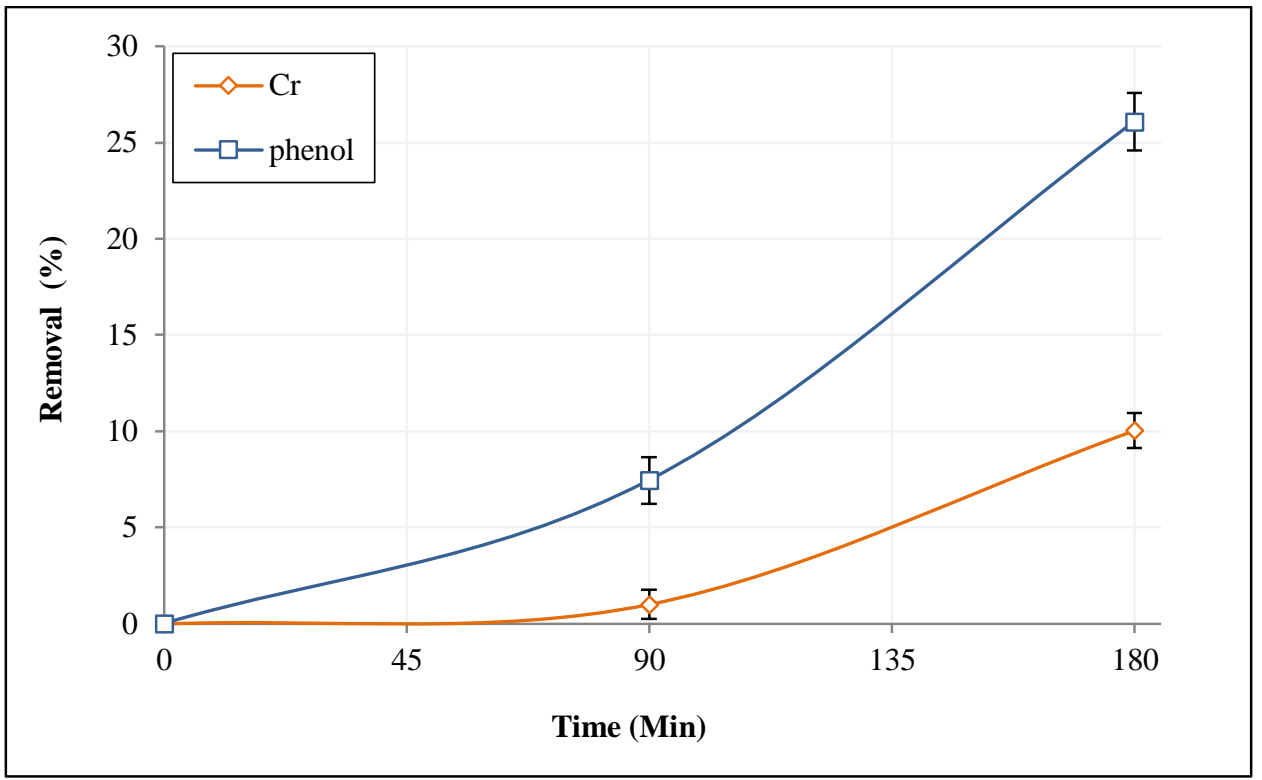

Figure 3. Interaction of phenol and chromium

According to Figure 3, it can be seen that in fist 90 min, chromium removal was very low (about 1\%); but after 180 min, the removal rate increased and reached to $10.03 \%$. for phenol, the removal rate in the first 90 min was lower than the removal rate in the second $90 \mathrm{~min}$. at the end of 3 hours of reaction, phenol removal rate reached to 26.08. this amount of reduction in pollutants removal occurred without use of any photocatalyst and radiation due to oxidation and reduction reactions, according to the following reaction (reaction 1), phenol was reduced and chromium (VI) was converted to chromium (III) [29]:

$14 \mathrm{Cr}_{2} \mathrm{O}_{7}^{2-}+3 \mathrm{C}_{6} \mathrm{H}_{6} \mathrm{O}+112 \mathrm{H}^{+} \leftrightarrow 28 \mathrm{Cr}^{3+}+18 \mathrm{CO}_{2}+65 \mathrm{H}_{2} \mathrm{O}$ 


\section{- Phenol and chromium removal in closed system by use of photocatalyst and UV radiation}

In these experiments, $250 \mathrm{ml}$ of solutions containing $50 \mathrm{mg} / \mathrm{l}$ phenol and chromium were placed in a beaker on a stirrer under UV radiation $(100 \mathrm{~W})$ and the impact of different concentrations of photocatalyst on the removal were examined, $\mathrm{pH}$ of 7 was considered as optimal $\mathrm{pH}$ for chromium and phenol removal.

\section{- Chromium removal}

Figure 4 shows the results of chromium removal under use of nanoparticles with different concentrations.

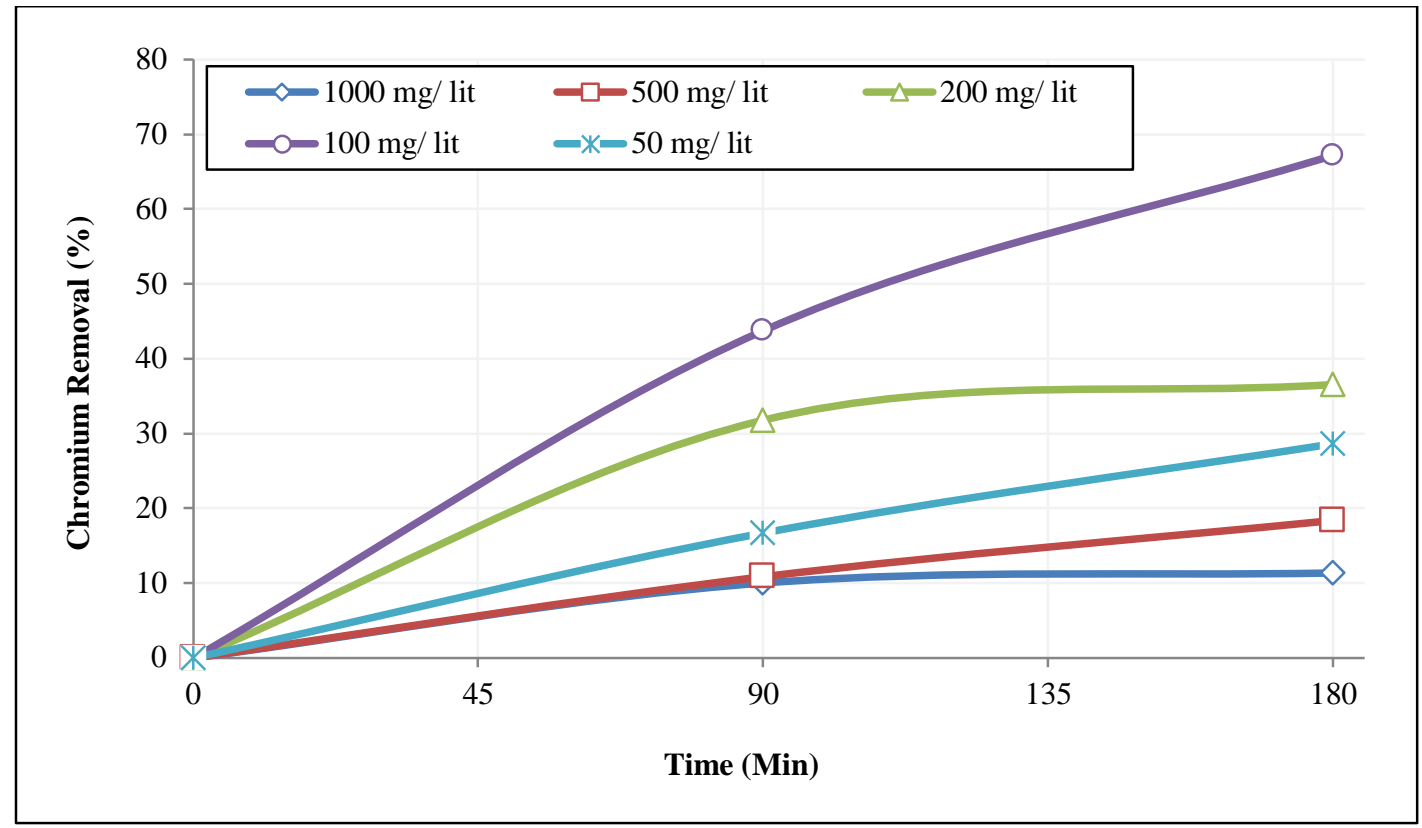

Figure 4. Chromium removal percentage by use of different concentrations of nanoparticle

As figure shows, when $1 \mathrm{~g} / \mathrm{l}$ photocatalyst was used, chromium removal was about $10 \%$ in first 90 min which did not significantly changed at the end of $180 \mathrm{~min}$. for the case of $500 \mathrm{mg} / \mathrm{l}$ of nanoparticle, chromium removal in the first 90 min was similar to the previous condition but removal continued with the same rate. When $200 \mathrm{mg} / \mathrm{l} \mathrm{was} \mathrm{applied}$ $32 \%$ removal was observed in the first sample which increased only by $5 \%$ at the end of 180 min. investigation of chromium removal by $50 \mathrm{mg} / \mathrm{l}$ of nanoparticles revealed that the slope of curve in the first 90 min is lower than the second 90 min implying that removal was faster at the beginning. When $100 \mathrm{mg} / \mathrm{l}$ photocatalyst was used for chromium removal, the rate of removal was $44 \%$ in first 90 min but reduction of concentration slowed down in the next 90 min.

Therefore, the highest rates of chromium removal were observed in concentrations of 100, 200, 50, 500 and 1000 $\mathrm{mg} / \mathrm{l}$ of photocatalyst, respectively. When $100 \mathrm{mg} / \mathrm{l}$ and $1 \mathrm{~g} / \mathrm{l}$ of photocatalyst were used, removal rate were $67.2 \%$ and $11.3 \%$, respectively.

\section{- Kinetics of chromium removal}

Kinetics of chromium removal at the presence of $\mathrm{TiO}_{2}(100 \mathrm{mg} / \mathrm{l}$ which had the highest impact) is depicted in Figure 5. 


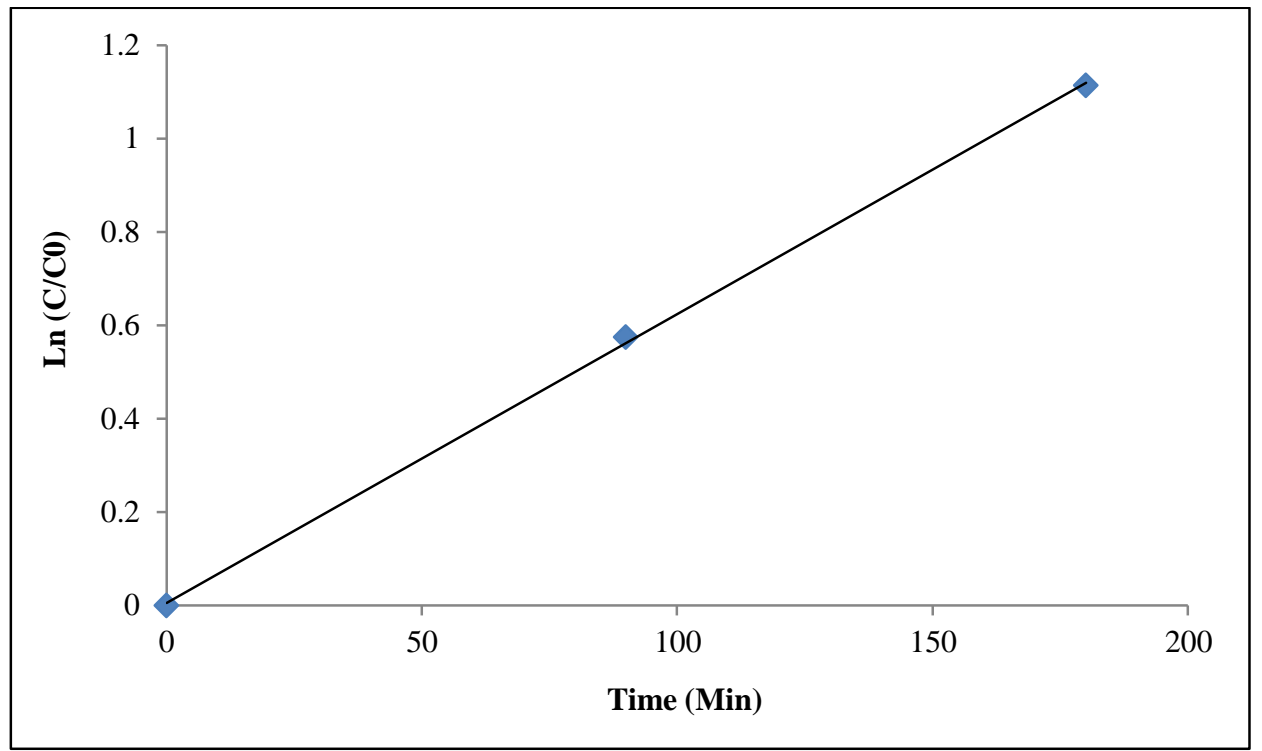

Figure 5. Kinetics model of chromium removal reaction

$\mathrm{R}^{2}=0.999$

Regarding the graph, the reaction is first-order and the speed of chemical reaction in the closed system containing slurry of nanoparticles could be defined as:

$\mathrm{C}=50 * \mathrm{e}^{-0.0062 \mathrm{t}}$

In which $\mathrm{C}$ and $\mathrm{t}$ are concentration and time and $\mathrm{k}$ shows the reaction speed.

\section{- Phenol removal}

Figure 6 reveals the results of phenol removal under different concentrations of photocatalyst.

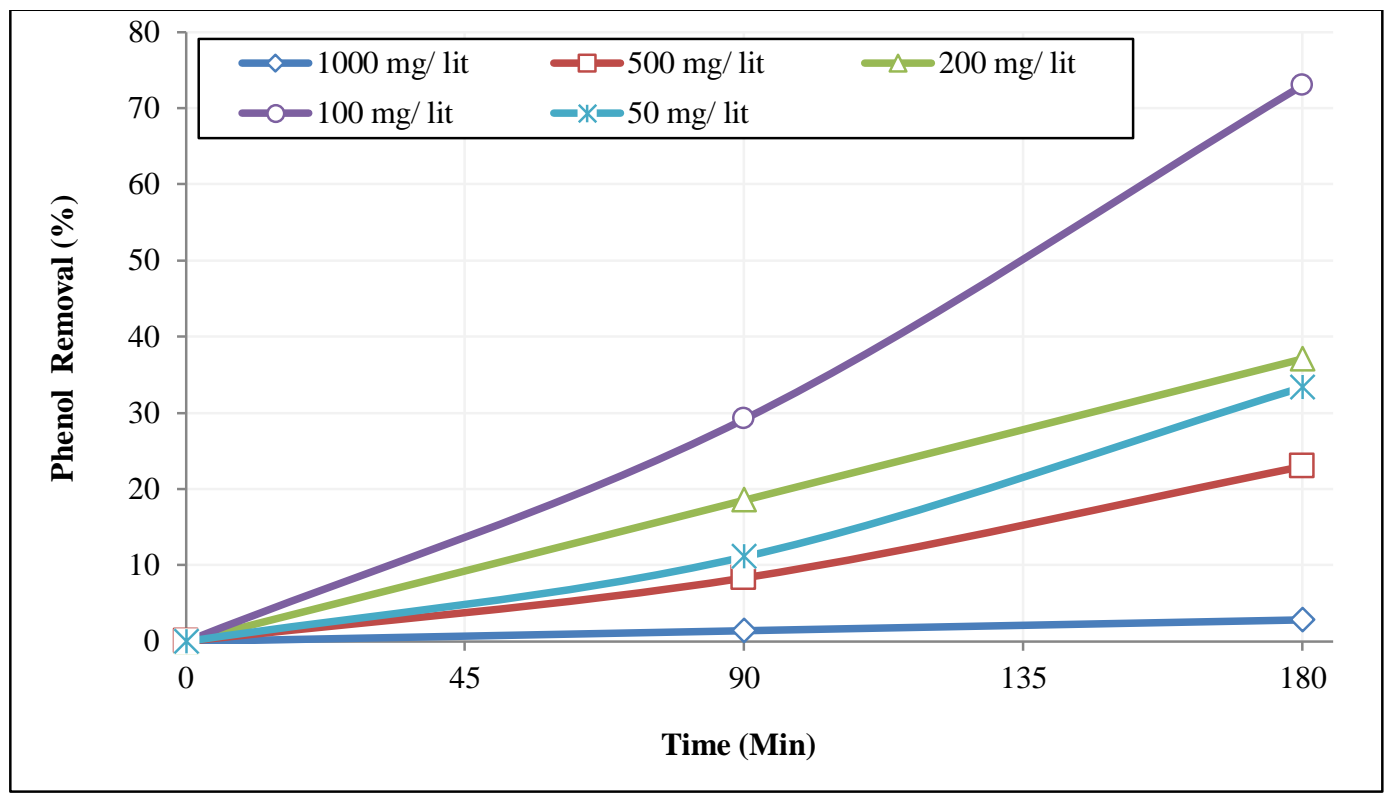

Figure 6. Phenol removal percentage under use of different concentrations of nanoparticle

As figure suggests, $1 \mathrm{~g} / \mathrm{l}$ of photocatalyst did not have significant impact on phenol removal. In case of 50 and 500 $\mathrm{mg} / \mathrm{l}$ of photocatalyst, removal rate had lower slope in the first $90 \mathrm{~min}$ and the rate increased at the interval of 90-180 $\mathrm{min}$. However, for the case of $200 \mathrm{mg} / \mathrm{l}$, the slope remained almost constant implying constant rate of phenol removal during all 3 hours. When $100 \mathrm{mg} / \mathrm{l}$ of photocatalyst was used, phenol removal rate was $30 \%$ in the first 90 min which accelerated in the second $90 \mathrm{~min}$.

Similar to the case of chromium removal, the highest rates of phenol removal were observed at concentrations of 
$100,200,50,500$, and $1000 \mathrm{mg} / \mathrm{l}$ of photocatalyst. When $100 \mathrm{mg} / \mathrm{l}$ and $1 \mathrm{~g} / \mathrm{l}$ of photocatalyst were used, removal rate were $72.3 \%$ and $2.7 \%$, respectively. These results were similar with the results of other researchers. For instance, Shahrezaei et al. also reported $\mathrm{TiO}_{2}$ photocatalyst concentration of $100 \mathrm{mg} / \mathrm{l}$ as the optimal concentration for phenol and its derivatives removal. Moreover, the optimal concentration of pollutant was reported as $100 \mathrm{mg} / \mathrm{l}$ [30].

Salah et al. obtained $92 \%$ phenol removal after 6 hours when $\mathrm{TiO}_{2}$ photocatalyst was employed. After 3 hours, the removal rate was $78 \%$ [31].

\section{- Kinetics of phenol removal reaction}

Figure 7 depicts the linear model of chromium removal by use of $100 \mathrm{mg} / \mathrm{l}$ nanoparticle.

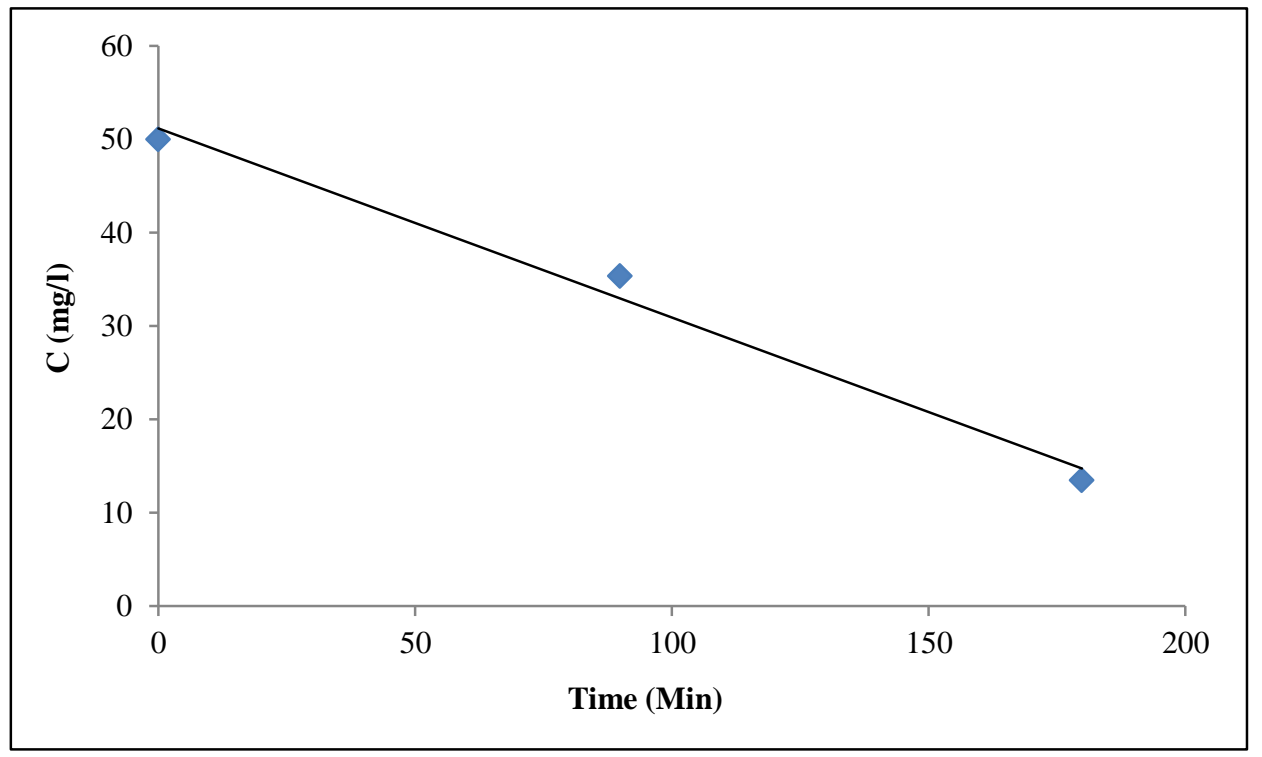

Figure 7. Kinetics of phenol removal reaction

$\mathrm{R}^{2}=0 / 986$

As the curve of concentration versus time was linear, therefore, the reaction order $(\mathrm{n})$ is zero and reaction equation can be defined as:

$\mathrm{C}=-0.203 * \mathrm{t}+50$

\section{Conclusion}

Interaction of phenol and chromium showed pollutant removal of $26.08 \%$ and $10.03 \%$, respectively after 180 min. In this system, pollutant removal was performed at $\mathrm{pH}=7$ under $\mathrm{UV}$ radiation with power of $100 \mathrm{~W}$ and the optimal concentration of photocatalyst was $100 \mathrm{mg} / \mathrm{l}$. Maximum phenol and chromium (VI) removal during $180 \mathrm{~min}$ at the presence of optimal nanoparticle concentration (in slurry form) was $72.9 \%$ and $67.2 \%$, respectively. Kinetics investigations showed that phenol removal reaction is zero-order while chromium (VI) removal is a first-order reaction.

\section{References}

[1] Yu, Kuang-Chung, Li-Jyur Tsai, Shih-Hsiung Chen, and Shien-Tsong Ho. "Chemical Binding of Heavy Metals in Anoxic River Sediments.” Water Research 35, no. 17 (December 2001): 4086-4094. doi:10.1016/s0043-1354(01)00126-9.

[2] Fasle Bahar, Sh and Emtiazjoo, M, Heavy Metals and Their Incurred Disturbances in Aquatic Organisms, Journal of Marine Science and Technology, 2009: p. 84-90.

[3] McLean, J.E. and B.E. Bledsoe, Behavior of metals in soils. EPA Environmental Assessment Sourcebook, 1992: p. 19-56.

[4] Rai, D., L.E. Eary, and J.M. Zachara. "Environmental Chemistry of Chromium.” Science of The Total Environment 86, no. 1-2 (October 1989): 15-23. doi:10.1016/0048-9697(89)90189-7.

[5] United States Environmental Protection Agency- standard 1995a.

[6] United States Environmental Protection Agency- standard 1995b.

[7] WHO 1996. Guidelines for Drinking-Water Quality. 2nd ed. Vol 2: Health Criteria and Other Supporting Information. 
Geneva:World Health Organization.

[8] Xie, Baoping, Hanxia Zhang, Peixiang Cai, Rongliang Qiu, and Ya Xiong. "Simultaneous Photocatalytic Reduction of Cr(VI) and Oxidation of Phenol over Monoclinic BiVO4 Under Visible Light Irradiation.” Chemosphere 63, no. 6 (May 2006 ): $956-963$. doi:10.1016/j.chemosphere.2005.08.064.

[9] Wang, Kuo-Hua, Yung-Hsu Hsieh, Ming-Yeuan Chou, and Chen-Yu Chang. "Photocatalytic Degradation of 2-Chloro and 2Nitrophenol by Titanium Dioxide Suspensions in Aqueous Solution.” Applied Catalysis B: Environmental 21, no. 1 (May 1999): 18. doi:10.1016/s0926-3373(98)00116-7.

[10] World Health Organization, Phenol; health and safety guide. 1994.

[11] Rengaraj, S. "Removal of Phenol from Aqueous Solution and Resin Manufacturing Industry Wastewater Using an Agricultural Waste: Rubber Seed Coat.” Journal of Hazardous Materials 89, no. 2-3 (January 28, 2002): 185-196. doi:10.1016/s03043894(01)00308-9.

[12] Barakat, M.A. "New Trends in Removing Heavy Metals from Industrial Wastewater." Arabian Journal of Chemistry 4, no. 4 (October 2011): 361-377. doi:10.1016/j.arabjc.2010.07.019.

[13] Agrawal, Archana, Chandana Pal, and K.K. Sahu. "Extractive Removal of Chromium (VI) from Industrial Waste Solution." Journal of Hazardous Materials 159, no. 2-3 (November 2008): 458-464. doi:10.1016/j.jhazmat.2008.02.121.

[14] Park, Donghee, Yeoung-Sang Yun, and Jong Moon Park. "Mechanisms of the Removal of Hexavalent Chromium by Biomaterials or Biomaterial-Based Activated Carbons.” Journal of Hazardous Materials 137, no. 2 (September 21, 2006): $1254-1257$. doi:10.1016/j.jhazmat.2006.04.007.

[15] Ehrampoosh, M., et al., Removal of methylene blue dye from textile simulated sample using tubular reactor and TiO2/UV-C photocatalytic process. Journal of Environmental Health Science \& Engineering, 2011. 8(1): p. 34-40.

[16] Low, Fiona Chai Foong, Ta Yeong Wu, Chee Yang Teh, Joon Ching Juan, and N Balasubramanian. "Investigation into Photocatalytic Decolorisation of CI Reactive Black 5 Using Titanium Dioxide Nanopowder." Coloration Technology 128, no. 1 (October 3, 2011): 44-50. doi:10.1111/j.1478-4408.2011.00326.x.

[17] De Lima, Carlos Antônio Pereira, Geralda Gilvânia Cavalcante de Lima, and Fernando Fernandes Vieira. "Effluent Treatment of Synthetic Tanning by Nanomaterials Photocatalytic." Materials Science Forum 869 (August 2016): 784-788. doi:10.4028/www.scientific.net/msf.869.784.

[18] Satyro, Suéllen, Raffaele Marotta, Laura Clarizia, Ilaria Di Somma, Giuseppe Vitiello, Marcia Dezotti, Gabriele Pinto, Renato F. Dantas, and Roberto Andreozzi. "Removal of EDDS and Copper from Waters by TiO2 Photocatalysis under Simulated UV-solar Conditions." Chemical Engineering Journal 251 (September 2014): 257-268. doi:10.1016/j.cej.2014.04.066.

[19] Gondal, M. A., M. A. Dastageer, S. G. Rashid, S. M. Zubair, M. A. Ali, D. H. Anjum, J. H. Lienhard, G. H. Mckinley, and K. Varanasi. "Plasmon Resonance Enhanced Photocatalysis under Visible Light with $\mathrm{Au} / \mathrm{Cu}-\mathrm{TiO}<\mathrm{SUB}>2</ \mathrm{SUB}>\mathrm{Nanoparticles:}$ Removal Cr (VI) from Water as a Case of Study." Science of Advanced Materials 5, no. 12 (December 1, 2013 ): $2007-2014$. doi:10.1166/sam.2013.1669.

[20] Naimi-Joubani, Mohammad, Mehdi Shirzad-Siboni, Jae-Kyu Yang, Mitra Gholami, and Mahdi Farzadkia. "Photocatalytic Reduction of Hexavalent Chromium with Illuminated $\mathrm{ZnO} / \mathrm{TiO} 2$ Composite.” Journal of Industrial and Engineering Chemistry 22 (February 2015): 317-323. doi:10.1016/j.jiec.2014.07.025.

[21] Djellabi, Ridha, Fouzi M. Ghorab, Sana Nouacer, Abdelaziz Smara, and Ouahida Khireddine. "Cr (VI) Photocatalytic Reduction Under Sunlight Followed by Cr(III) Extraction from TiO 2 Surface.” Materials Letters 176 (August 2016): 106-109. doi:10.1016/j.matlet.2016.04.090.

[22] Nguyen, Vi Nu Hoai, Rose Amal, and Donia Beydoun. "Effect of Formate and Methanol on Photoreduction/removal of Toxic Cadmium Ions Using TiO2 Semiconductor as Photocatalyst." Chemical Engineering Science 58, no. 19 (October 2003): $4429-4439$. doi:10.1016/s0009-2509(03)00336-1.

[23] Lei, L., Y. J. Jin, T. Wang, X. Zhao, Y. Yan, and W. Liu. "Simultaneous Removal of Cd (II) and Phenol by Titanium DioxideTitanate Nanotubes Composite Nanomaterial Synthesized Through Alkaline-Acid Hydrothermal Method." Huan jing ke xue= Huanjing kexue 36, no. 7 (2015): 2573-2580.

[24] Zhang, D., A. Wei, J. Zhang, and R. Qiu. "The Photocatalytic Interaction of Cr (VI) Ions and Phenol on Polymer-Modified TiO2 Under Visible Light Irradiation.” Kinetics and Catalysis 56, no. 5 (September 2015): 569-573. Doi: 10.1134/s0023158415050195.

[25] Samarghandi, M. R., J. Nouri, A. R. Mesdaghinia, A. H. Mahvi, S. Nasseri, and F. Vaezi. "Efficiency Removal of Phenol, Lead and Cadmium by Means of UV/TiO2/H2O2 Processes." International Journal of Environmental Science \& Technology 4, no. 1 (January 1, 2007): 19-25. doi:10.1007/bf03325957.

[26] Papadam, Theodora, Nikolaos P. Xekoukoulotakis, Ioannis Poulios, and Dionissios Mantzavinos. "Photocatalytic transformation 
of acid orange 20 and $\mathrm{Cr}$ (VI) in aqueous TiO2 suspensions." Journal of Photochemistry and Photobiology A: Chemistry 186, no. 23 (2007): 308-315.

[27] PHENOLICS (SPECTROPHOTOMETRIC, MANUAL 4-AAP WITH DISTILLATION)-METHOD 9065, Environmental Protection Agency.

[28] CHROMIUM, HEXAVALENT (COLORIMETRIC)-METHOD 7196A, Environmental Protection Agency.

[29] Benjamin, M.M., Water chemistry. 2014: Waveland Press.

[30] Shahrezaei, F., A. Akhbari, and A. Rostami, Photodegradation and removal of phenol and phenolic derivatives from petroleum refinery wastewater using nanoparticles of TiO2. IJEE, 2012. 3(2): p. 267-274.

[31] Hadj Salah, N., M. Bouhelassaa, S. Bekkouche, and A. Boultii. "Study of Photocatalytic Degradation of Phenol." Desalination 166 (August 2004): 347-354. doi:10.1016/j.desal.2004.06.089. 